\title{
Assessing the Quality Improvement Associated with Pending Referral Requests at MNG-HA, Saudi Arabia
}

Tahani Daghistani ${ }^{1 *}$, Huda AIGhamdi', Ebtisam Al Ghamdi', Hisham Al Maimony², Talal Al Harbi ${ }^{3}$, and Raed H. AlHazme ${ }^{1}$

${ }^{1}$ Information Systems and Informatics Division, Ministry of National Guard-Health Affairs, Riyadh, Saudi Arabia

${ }^{2}$ Ambulatory Care Operation, King Abdulaziz Medical City, Ministry of National Guard-Health Affairs, Riyadh, Saudi Arabia

${ }^{3}$ Ambulatory Care Operation, King Abdullah

Specialized Children Hospital, Ministry of National

Guard-Health Affairs, Riyadh, Saudi Arabia
This article was published in the following Scient Open Access Journal:

Open Access Journal of Public Health

Received February 25, 2020; Accepted March 05, 2020; Published March 11, 2020

\begin{abstract}
Referral system supports the directing of patient to an appropriate facility or specialty. Avoiding delay in referral requests decrease waiting lists and increase effectiveness of referral system, this leads to smooth referral process, and ease communication between all levels of the health system. This study uses Ministry of National Guard Health Affairs, Saud Arabia to assess using escalation emails (technical intervention) as a way to improve quality of referral system. This solution was applied to identify the pending requests and escalate them to different departmental levels to speed the process. The intervention resulted in a trend of reduction in the percentage of requests either accepted or rejected; and thereby an improvement in the quality of referral system was achieved.
\end{abstract}

Keywords: Referral Requests, Technical Intervention, Healthcare Improvement.

\section{Introduction}

In line with the health system in Saudi Arabia, Ministry of National Guard Health Affairs (MNG-HA) provide three categories of healthcare services, which are classified as primary, secondary and tertiary. Nowadays, patient referrals are a common practice in healthcare setting with aim to seek advice, specialty consultations for advance and complex cases [1]. Referral system supports the transfer from one level of the healthcare system to higher levels for patients attending a healthcare facility that has insufficient resources to the most appropriate specialist or facility with better level of services [2-4]. Healthcare organizations know that referrals are a critical especially with growing demand for specialty care. Pending or delaying referral requests is the most common barrier to a well-functioning referral system. The resulting gap is due to the poor communication and coordination between all parts, workflow and workload. This, in turn, makes timely access to specialty services more challenging, hence inefficiencies in quality of healthcare and suboptimal outcomes [5]. In order to overcome such barriers, a technical intervention is needed to streamline the referral process and reduce pending referrals in order to improve overall process effectiveness [4]. This study aims to assess whether escalation emails (technical intervention) would be practical at our facility to reduce the frequency of pending referral requests (accept, reject).

\section{Methods}

This study was completed at MNG-HA in Riyadh, a tertiary care hospital, for two cases. The referring medical department transfers the case to the related receiving medical department. The first case included pending requests (no decision) that need to be processed by the receiving medical department, requests were assessed between July 2017 and July 2018. The second case included pending rejected requests that need to be processed by the referring medical department, requests were assessed between October 2017 and September 2018. Hence, an escalation email was recommended as solution by Information System and Informatics Division (ISID). This service used to identify the pending requests and escalate them to different departmental levels to speed the process [6]. In both directions (accept or reject), a daily escalation email about the number of pending referral requests was sent for more than 5 days, 10 days and 15 days to the department head, to the department chairman and then medical services, respectively.
Corresponding author: Tahani A. Daghistani, Senior Programmer Analyst, Information Systems and Informatics Division, Ministry of National Guard-Health Affairs, King Abdullah International Medical Research Center, King Saud bin Abdulaziz University for Health Sciences, Department Mail Code: 9100, P.O. Box 22490, Riyadh 11426, Kingdom of Saudi Arabia. 


\section{Results}

The overall impact of the study was to reduce the frequency of referral requests by the post implementation period. The project results showed a trend of reduction in the percentage of referral requests, which continued more than five points after the intervention for both accepted and rejected requests.

Figure 1 shows the percentage of pending referral requests for more than 10 days before and after technical intervention. This improvement presented a steady trend decrease in pending cases until reaching $7.87 \%$ in July 2018 of the post intervention period.

Figure 2 shows the number of pending rejected referral requests for more than 10 days before and after technical intervention. The referral rate dropped to $8.22 \%$ in the post intervention period. However, in August 2018 there were increased rejected pending cases which were still less than the average of pre implementation period.

\section{Discussion}

In this study, we assess the quality improvements associated with referral requests in MNG-HA. The findings demonstrate that escalation email is a practical solution and significantly reduces referral requests either accepted or rejected. Promoting timely health information sharing and exchange during the referral process fully supported by electronic health record (EHR) systems are strongly recommended. This facilitates communication and smooth transfer of care responsibilities for patients. Limited functionality in EHR involves integration into clinical workflow and contributes to increased workload, pending cases, and patient safety risks. A better understanding of health information; how and when it changes across multiple steps of the referral process is needed [7].

In the current electronic health record (EHR) system, there is a notification feature for a new referral request only. Healthcare organizations need to have taken steps to amend advance features that do not appear to be supported by current EHR. For example, evaluation of the priority of the referral requests and receipt of timely feedback upon rejection, approval, or completion of each referral request $[7,8]$. In fact, current EHR have not yet reached their potential and no available system can fully support most referral processes. Reasons behind this included complexity and variability of referral process across healthcare organization. In addition to lack of standardization of referral practices, the complete standardization is impossible. Accordingly, EHR need to be customized to reflect unique requirements of the organization [8].

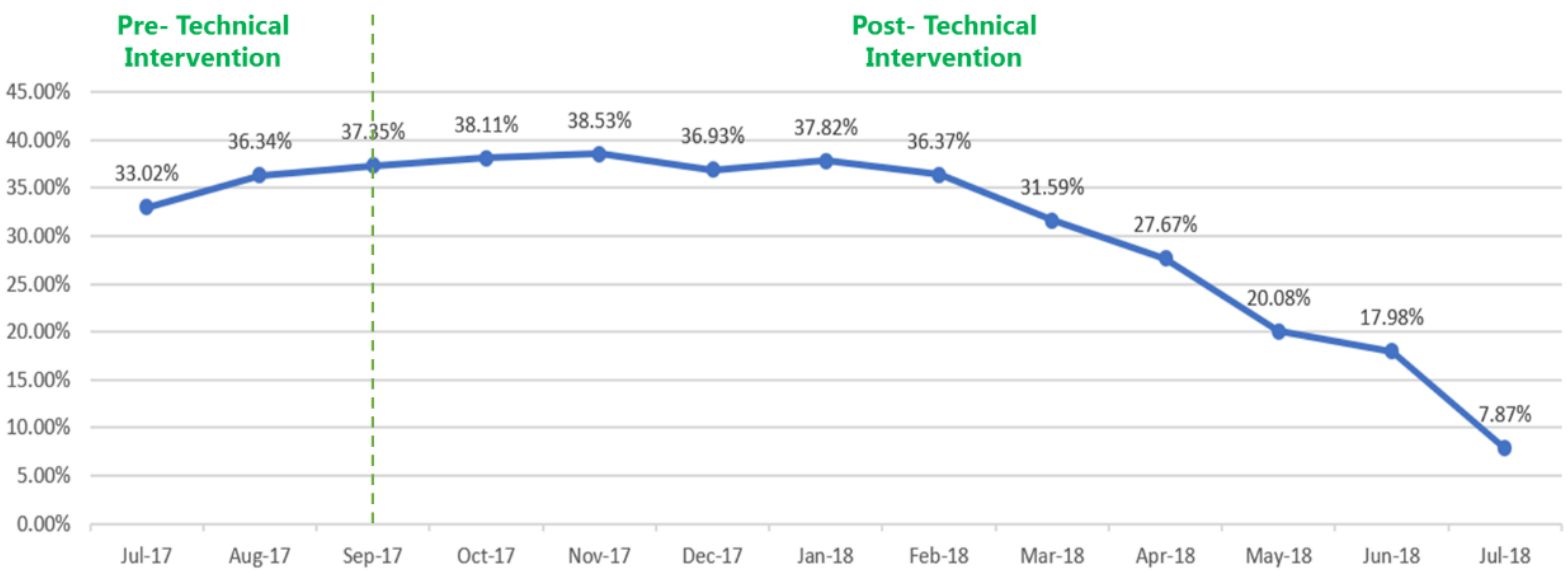

Figure 1: The percentage of pending referral at $A C C$ for more than 10 days

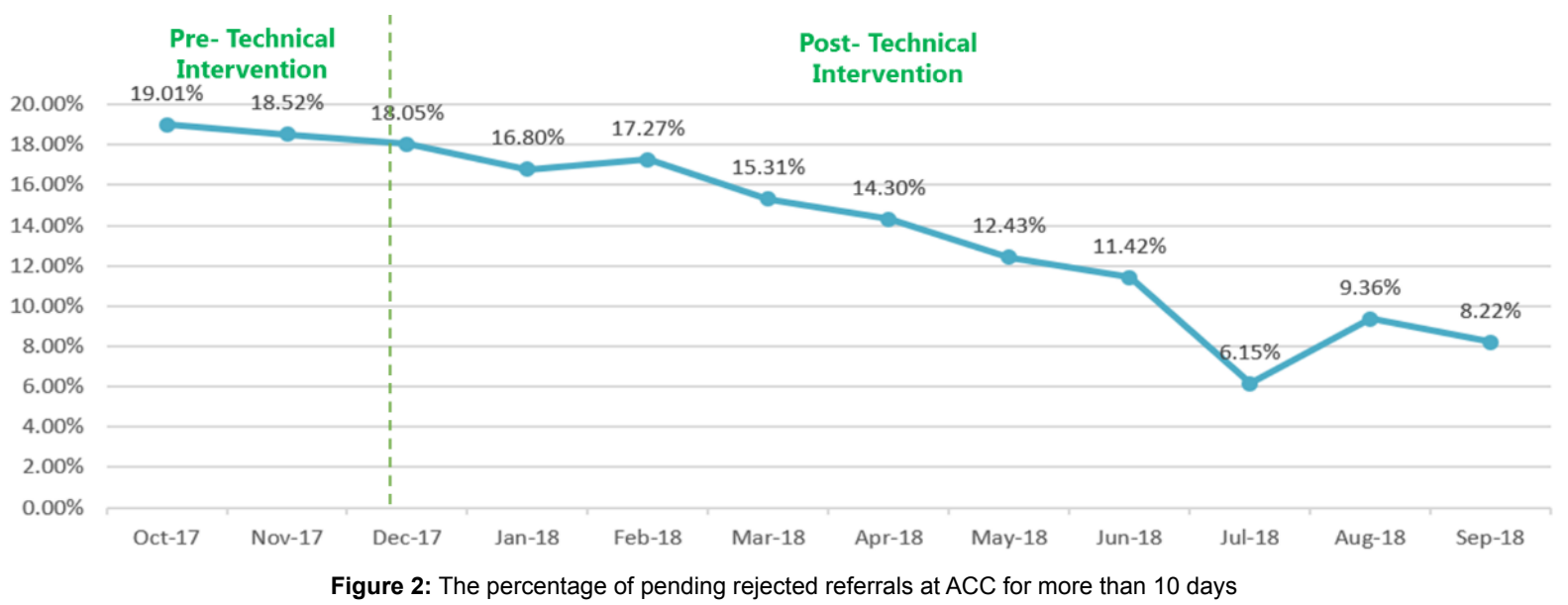




\section{Contributors Contributorship Statement}

TD planned the study and write the manuscript, $\mathrm{HG}$ review and edited the manuscript, EG collect and analyze data, $\mathrm{RH}$ implemented the study, HM implemented the study, TH implemented the study.

\section{Funding}

The authors have declared a grant for this research from Information Systems and Informatics Division at Ministry of National Guard-Health Affairs.

\section{Competing interests}

None declared

\section{Acknowledgement}

None

\section{References}

1. Alshami $M$, Almutairi $S$, Househ $M S$. The implementation experience of an electronic referral system in saudi arabia: a case study. In ICIMTH. 2014;138-141.
2. Akbari A, Mayhew A, Al-Alawi MA, et al. Interventions to improve outpatient referrals from primary care to secondary care. Cochrane Database Syst Rev. 2005;20;(3):CD005471.

3. Omotosho A, Adegbola O, Adebo A. A patient-based hospital referral decision support system. International Journal of Computer Application. 2016;115(10):38-43.

4. Alkinaidri A, Alsulami H. Improving healthcare referral system using Lean Six Sigma. American Journal of Industrial and Business Management. 2018;11;8(02):193-206.

5. Bell D, Straus S, Wu S, Chen A, Kushel M. Use of an electronic referral system to improve the outpatient primary care-specialty interface: final report. Agency Healthcare Res Qual. 2012;11(12):0096.

6. AIRabiah F, AlKhashan N, AIGhamdi $\mathrm{H}$. The use of healthcare IT to reduce waiting time of patient's pending referrals at MNGHA. Computer Methods and Programs in Biomedicine. 2019;1(171):11-12.

7. Savoy A, Militello L, Diiulio J, et al. Cognitive requirements for primary care providers during the referral process: Information needed from and interactions with an electronic health record system. International Journal of Medical Informatics. 2019;129:88-94.

8. Esquivel A, Sittig D F, Murphy DR, Singh H. Improving the effectiveness of electronic health record-based referral processes. BMC Med Inform Decis Mak. 2012;12(1):107.

Copyright: ( 2020 Tahani A. Daghistani, et al. This is an open-access article distributed under the terms of the Creative Commons Attribution License, which permits unrestricted use, distribution, and reproduction in any medium, provided the original author and source are credited. 